\title{
Outside the classroom: Community health education to prevent diseases in South Bahia, Brazil.
}

\author{
V N C Leal*, N P Santos*, M L Santos*; P S Mendes*, T A G Pellizzoni*, M F Silva**. \\ * Biomedical Sciences, State University of Santa Cruz, Ilhéus, Bahia, Brazil; * * Department of \\ Biological Sciences, State University of Santa Cruz, Ilhéus, Bahia, Brazil
}

\begin{abstract}
The objective of this paper was to report the achievements of a workgroup which was focused on outside of classroom activities linked to the social demands of primary health care to improve the learning of diseases among health students in South Bahia, Brazil. The methodology encompassed a pedagogical approach including local diagnostic of health and development of strategy actions of continuing education on health promotion. This has strengthened the development of new teaching resources that favored the learning of the biology of diseases frequently found in these communities. While on the one hand it has improved the quality of information on health in self-care and sexually transmitted diseases, on the other hand it has helped health students develop skills and acquire competencies aligned to the principles of health promotion. The authors suggest that continuing education activities are the best strategies underlying the mechanisms of collective knowledge and the relations between learning and practical action. New approaches on health education span the notions of individual and family hygiene and practices in health, with emphasis on prevention and prophylaxis, which are the objectives of programs health promotion and disease prevention.
\end{abstract}

Keywords: Health; Education; Meaningful learning; Brazil

\section{Introduction}

Experiences outside the classroom can be defined as any learning experience with benefits for both students and community. The range of the benefits to higher education students depends on their ability to comprehend the reality and their interest for meaningful learning; in the dimension of social benefits, they allow the exchange of knowledge between community and University and stimulate healthier habits (Falcão Júnior et al., 2007). A community health profile consists of indicators of sociodemographic characteristics, health status and quality of life, health risk factors, and the health human resources that are relevant for most communities (Durch et al., 1997). Interdisciplinary outside of classroom programs are thought to be the strategies that better emphasize improvement of life quality for individuals and families lacking financial resources and living in inequity (Whitehead et al. 2001). In the case of this paper, examples of health risks of great social importance stand out as sexually transmitted diseases (STDs). This can be explained by the high incidence of STDs worldwide, especially among the least developed countries (Bhutta et al., 2014).

In the late twentieth century, one of the Brazilian Sanitary Reform movement's claims was to improve the training of health students from the perspective of linking the social needs to the formation of a better health professional, which would act as a generalist and critic, obedient to the principles of the Brazil's Unified System of Health - SUS (National Council of Education, 2001).

The State University of Santa Cruz (UESC) promotes continuing education activities on the basis of the social demands of South Bahia, Brazil. The city of Ilhéus has 184,236 inhabitants distributed in $1,760,111 \mathrm{~km}^{2}$. The population chiefly concentrates in urban areas (84\%), and the average income per capita is US\$ 506.00 monthly. Of the total population, 15,685 individuals are subjected to inadequate sanitation conditions. Itabuna has 204,667 inhabitants distributed in $432,244 \mathrm{~km}^{2}$ and $97 \%$ of the total 
population lives in urban areas. The average income per capita is US\$ 554.00 monthly. The number of residents in private households with inadequate sanitary conditions is 4,790 people. (Brazilian Institute of Geography and Statistics, 2014).

Thus, increasing urbanization associated with the growth of population, especially in Ilhéus, favors the emergence of unplanned communities and the consequent lack of access to basic services, inadequate housing conditions and exposure to various environmental contaminants. (Fontes et al., 2010). This contributes to the low quality of life and health, as observed in other cities and regions. (Graham et al., 2004; Shobha et al., 2013). Infectious diseases are closely enmeshed to sanitary conditions and public health, with higher prevalence among individuals of low socioeconomic status, which contributes to increased rates of morbidity and mortality especially in infants and children. (Korkes et al., 2009; UNAIDS, 2013).

Thus, beyond the best infrastructure and sanitation, the improvement of life quality greatly depends upon the performance of professionals committed to health education, under the aegis of the SUS, in encouraging self-care and promoting comprehensive health care. (Flavigna et al, 2013). The objective of this study was to report the experience of the continuing education program in the development of skills and competencies of forthcoming health professionals while addressing the strategies on biological and health education linked to social demands of South Bahia, Brazil.

\section{Material and Methods}

\section{Subjects and ethical implications}

The study was conducted from January 2011 to November 2013, and started by accessing public databases to select indicators of social, demographic and health conditions of the communities in the vicinity of UESC. The city of Ilhéus, more specifically, the villages of Juerana, Sambaituba, Urucutuca, and Teotônio Vilela were chosen. Initially, a meeting was scheduled for discussing the importance, ethical implications, and the acceptance of the study by all community leaders, children, parents, health professionals or directors of schools. Only fully informed volunteers participated in the study, in line with the Brazilian regulatory act on ethics and research with human volunteers. (National Council of Health, 2012). The study was approved by the ethics committee of the State University of Santa Cruz and all subjects, or its legal representatives, gave written informed consent. The sample size was calculated at a confidence level of $95 \%$. Then calculated study population size was 280 .

\section{Continuing education activities}

Secondary meetings were again scheduled to deliver results and discuss the scenario of contamination with parents, community leaders, health professionals or responsible for the schools. At that time, there were lectures, workshops, music and sketches for children and adults regarding most prevalent diseases and STD. In the same way, there have been orientations on the importance of preventing individuals and families, as well as medical care, in order to have efficient treatment.

\section{Assessment of health education}

After the survey on health conditions, children and adults were evaluated for previous information by applying an appropriated questionnaire that evaluated the level of knowledge on the prevention of STD. Briefly, volunteers respond to questions by raising a card with the answer they considered correct, according to their previous 
knowledge. After that, each STD was presented in the form of interactive lecture, in which participants had the opportunity to watch content on the etiology, transmission, symptoms and prevention of the most prevalent STD. After the lecture and the presentation of songs and plays, the same questions were reapplied and the overall hit rate was calculated. Health students were also evaluated on the impact on learning and acquiring of competences and skills along the experience in the communities.

\section{Statistical analysis}

Chi-square test $\left(\mathrm{X}^{2}\right)$ was used to evaluate the significance of the results in the application of questionnaires to assess health education. It was considered as the expected responses the equitable apportionment among all the alternatives compared to the amount of correct answers observed before and after the continuing education activities. The significant level was 5\%. Data were analyzed by using GraphPad Prism 4.

\section{Results and Discussion}

The continuing education experiences included multiple approaches: community visits, completion of questionnaires and the production of resources for recreational and educational activities in the communities. Despite there were differences between the epidemiological surveys conducted at each of the four selected communities, the most significant results were observed in Teotonio Vilela. This result allowed for developing instructional resources for educational purposes, with a focus on the most frequent diseases, mainly STD.

In order to increase the bond of students with the community during activities and enable the development of humanistic actions, recreational and educational alternatives were important so as to better understand the health-disease process and self-care, both from the individual and the community. In effect, this is essential to promote a more comprehensive health care. This fact entails the community experience, as it allows the interaction between theory and practice and awakening of vocation for public health and humanitarian care. Accordingly, the authors highlight the contribution of health promotion, which is linked to community action in the training of students, in line with the new curriculum guidelines for healthcare careers in Brazil (Lopes Neto, 2007).

In the Table I it is depicted the socioeconomic profile of Teotonio Vilela; one can easily note the prevalence of low family income and educational levels among inhabitants. In this scenario, under a broader conception of health education, it is considered that, in order to educate an adult to self-care, one must do more than expose health as advertising or give loose information. We have evaluated the accuracy of prior information provided by adults on the prevention of STDs before and after recreational and educational activities. The overall results depicted in Figure 1 pointed out that the ludic and pedagogical approaches of adults were significant $(p<0.05)$ in the acquisition of new knowledge about prevention of STDs since the correct rate of individual and general issues were higher after educational actions were presented. It can be noticed that, in such case, adult education is a voluntary process which provides resources that spark the interest of the individual health.

The experience on health education contributes to improve the learning of parasitc diseases and STDs among biology and health students. It was possible to calculate the positive self-assessment of health students (100/82) on dedication to the activities 
(acting, planning and collaborating; $\mathrm{X}^{2}=16.97$ and $p<0.001$ ) also on the reaction of the audience (participatory, curiosity and sympathy; $X^{2}=9.97$ and $p<0.01$ ) to the educational resources available.

One limitation of the study was the sample size not very representative of the population due to the lacking of fully validated questionnaires, which caused a higher exclusion index. Despite these facts, this study has revealed that health education should be incorporated on everyday basis in the classroom and, for this purpose the activities must be replaced from conventional classes to extramural experience. We assume that universities are built from their subjects, teachers or students so as to improve their practices and educational projects. UESC makes a significant and original contribution in the training of human resources for public health aligned to SUS (Paim et al., 2011). It appears that the formal education on health lacks more comprehensive approaches that combine the essential characteristics of diseases under different learning perspectives. Changing the meaning perspectives or health habits serve as perceptual and cognitive codes to structure the way one perceives, thinks, feels, and acts on one's health care.

Table 1. Socio-demographic characterization of Teotonio Vilela. Ilhéus. Bahia, Brazil

\begin{tabular}{lcc} 
Table 1. Socio-demographic characterization of Teotonio Vilela. Ilhéus. Bahia, Brazil \\
\hline & $\mathbf{n}(\%)$ & $\mathbf{p}$ \\
Education & & 0,001 \\
Illiterate & $2(1,7)$ & \\
Primary & $34(29,05)$ & \\
Secondary & $79(67,52)$ & \\
Higher & $1(0,85)$ & 0,001 \\
Undeclared & $1(0,85)$ & \\
& & \\
Family income (MW) & & \\
Up to 1 MW & $93(79,48)$ & \\
Between 2 and 3 MW & $22(18,80)$ & \\
Above 4 MW & $1(0,85)$ & \\
Undeclared & $1(0,85)$ & \\
& & \\
Gender & & \\
Female & $69(58,97)$ & \\
Male & $48(41,02)$ &
\end{tabular}

MW: Minimum Wage 


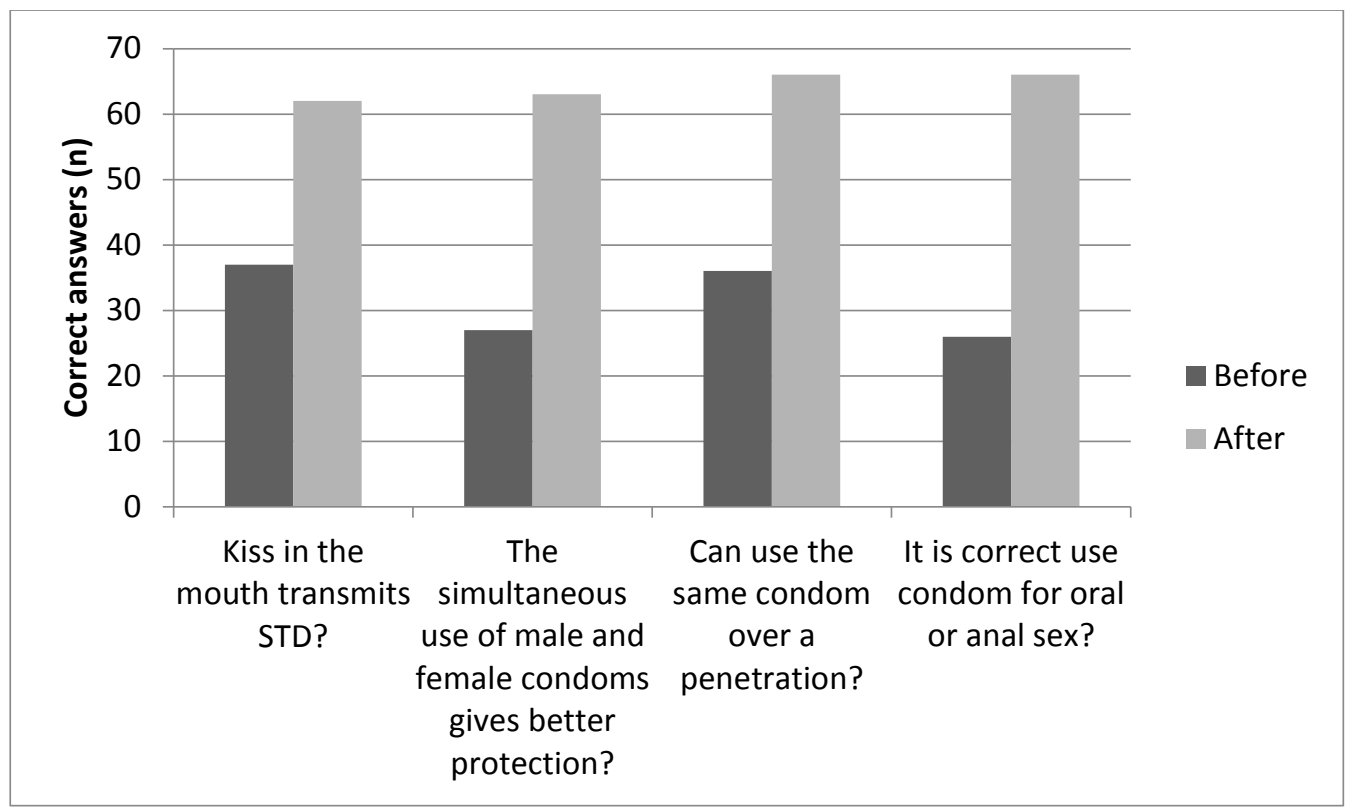

Figure 1. Examples of the STD prevention before and after ludic and pedagogical approaches. All differences were considered significant (Chi-square test $p<0,05$ ).

\section{Conclusions}

The authors conclude that the outside of the classroom experiences contributed to better understand of STD in the community. The continuing health education activities helped the students to develop fundamental skills for health promotion, awake collective and social transformation through education in order to reduce the incidence STDs in South Bahia, Brazil.

\section{References}

Barreto, M. L., Genser B., Strina A., Teixeira G., Assis A. M., Rego R. F., Teles C. A., Prado M. S., Matos S., Santos D. N., Santos L. D., Cairncross, S. (2007). Effect of city-wide sanitation programme on reduction in rate of childhood diarrhoea in northeast Brazil: assessment by two cohort studies. The Lancet. 9599:1622-1628.

Brazil. (2012). Resolution 466/2012 from National Council of Health. Diário Oficial da União. 12:59-62.

Brazil. National Council of Education. Resolution cne/ces $n^{\circ} 4$, of 7 november 2001: Retrieved April 2014 ,

from: (http://portal.mec.gov.br/cne/arquivos/pdf/CES04.pdf)

Bhutta, Z. A., Sommerfeld, J., Lassi, Z.S., Salam, R. A., Das, J.K. (2014). Global burden, distribution, and interventions for infectious diseases of poverty. Infectious Diseases of Poverty. 3:21-28.

Durch J. S., Bailey L. A., Stoto M. A. (1997).Committee on using performance monitoring to improve community health. In: Improving Health in the Community: A Role for Performance Monitoring. Washington, DC: National Academy Press. 496.

Falcão Júnior, J.S.P. et al. (2007). Perfil e práticas sexuais de universitários da área de saúde. Esc Anna Nery R Enferm. 11 (1): 58 - 65 
Flavigna A., Canabarro C. T., Medeiros G. S. l. (2013). Health system and medical education in Brasil: history, principles and organization. World Neurosurgery. 80:723-727.

Fontes E.O., Souza T.P. (2010). Transformações ambientais no município de Ilhéus: uma análise da vulnerabilidade social. VI Seminário latino-americano de geografia física II Seminário ibero-americano de geografia física Universidade de Coimbra. Retrieved August 2014, from:

(http://www.uc.pt/fluc/cegot/VISLAGF/actas/tema3/ednice)

Graham J., Gurian P., Corella-Barud V., Avitia-Diaz, R. (2004). Periurbanization and in-home environmental health risks: the side effects of planned and unplanned growth. Int J Hyg Environ Health. 207:447-454.

Brazilian Institute of Geography and Statistics. Retrieved August 2014, from: (http://cidades.ibge.gov.br/painel/painel.php?codmun=291360).

Korkes F., Kumagai F. U., Belfort R. N., Szejnfeld D., Abud T. G., Klienman A., Florez G. M., Szejnfeld T., Chieffi P. P. (2009). Relationship between intestinal parasitic infection in children and soil contamination in an urban slum. $J$ Trop Pediatr. 55:42-45.

Lopes Neto D., Teixeira E., Vale E. G., Cunha F. S., Xavier I. M., Fernandes J. D., Shiratori K., Reinbnitz K. S., Sordi M. R. L., Barbieri M., Boccardi M. I. B. (2007). Adherece of nursing graduation courses to the national curricular guidelines. Rev Bras Enferm;60:627-34.

Nossa Ilhéus Institute Report (2012). Indicators for local actions on health. Kairós social development 2012. Retrieved August 2014, from: (http://nossailheus.org.br/indicadores/compara.html).

Paim J., Travassos C., Almeida C., Bahia L., .Macinko J. (2011).The Brazilian health system: history, advances, and challenges. The Lancet. 377:1778-179

Shobha M, Bithika D, Bhavesh S.The prevalence of intestinal parasitic infections in the urban slums of a city in Western India. J Infect Public Health 2013;6:142-9.

Toledo M. J. O., Paludetto A. W., Moura F. T., Nascimento E. S., Chaves M., Araújo S. M., Mota L. T. (2009). Evaluation of enteroparasite control activities in a kaingáng community of southern Brazil. Rev Saúde Pública. 43:1-10

Whitehead M, Dahlgren G, Gilson L. Developing the policy response to inequities in health: a global perspective. In: Challenging inequities in health care: from ethics to action. New York: Oxford University Press. 200, 309, 2001. 